\title{
Effect of antibiotic treatment on sputum elastase in bronchiectatic outpatients in a stable clinical state
}

\author{
RA STOCKLEY, SL HILL, HM MORRISON \\ From the General Hospital, Birmingham
}

ABSTRACT Broad spectrum antibiotic treatment was given on 21 occasions to 15 patients with bronchiectasis who regularly produced purulent, elastase positive secretions. Although the results showed that sputum clearing - that is, changing from purulent to mucoid-largely depended on the pathogenic organism isolated, this was not exclusively the case and in some cases sputum growing sensitive organisms failed to clear whereas clearing occurred in other samples containing resistant organisms or no obvious pathogens. Clearing of sputum was achieved eventually in 12 of the patients and this was associated with the disappearance of elastase activity, although it returned in 10 patients within one week of stopping treatment. There was no change in sputum elastase where the sputum failed to clear. The clearance of elastase activity was associated with a decrease in protein transudation into the lung secretions. The sputum:serum albumin concentration ratio fell $(\mathrm{p}<0.005)$ from a mean $(\mathrm{SD})$ of $2.32(1.56) \times 10^{-2}$ in these 12 patients before treatment to $1.09(0.40) \times 10^{-2}$ within the first week of treatment, but rose again to $2.07(1.29)$ $\times 10^{-2}$ within one week of stopping treatment. The results suggest that antibiotic treatment when patients are in a stable state may have a beneficial effect on the pathogenic nature of lung secretions and inflammation within the lung.

Elastase activity is frequently a feature of purulent secretions ${ }^{1}$ and it is found regularly in sputum from patients with bronchiectasis ${ }^{2}$ and cystic fibrosis ${ }^{3}$ even when they are in a clinically stable state. It has been suggested that this proteolytic activity may be relevant to the pathogenesis of the lung disease since purified neutrophil elastase has been shown to damage ciliated epithelium and reduce ciliary beat frequency in vitro. ${ }^{4}$

Direct evidence of such effects in vivo is lacking but can be inferred from several related studies. Firstly, the secretions of patients with bronchiectasis often contain elastolytic activity and this is associated with an increase in protein transudation into the lung from serum, suggesting a degree of bronchial epithelial damage or inflammation even in a stable clinical state. ${ }^{2}$ Secondly, ciliary activity has been shown to be reduced in patients with bronchiectasis $^{5}$ and, finally, the bronchial epithelium in such patients shows histological damage. ${ }^{6}$ The association of these changes with elastase activity does not necessarily indicate a cause and effect relationship; but such enzyme activity is of potential importance at least in the pathogenesis of progressive lung disease, which occurs in a proportion of such patients.

Previous studies in patients with chronic bronchitis have shown that the presence of elastase activity and a rise in the ratio of sputum to serum albumin are a feature of acute infection rather than the stable clinical state. ${ }^{7}$ Such episodes are associated with a change in sputum from mucoid to purulent, which is usually reversed by antibiotic treatment.

The present study was designed to assess the presence of elastase activity and measure the ratio of sputum to serum albumin in a group of stable outpatients with bronchiectasis who produce purulent sputum regularly. In particular, we were interested to see whether in these relatively symptom free patients changes in the sputum could be induced by broad spectrum antibiotics and to determine whether these might be of potential benefit.
Address for reprint requests: Dr RA Stockley, General Hospital, Birmingham B4 6NH.

Accepted 3 February 1984

\section{Methods}

Twenty one antibiotic studies were carried out in 15 
Table 1 Clinical details of the patients and results of routine lung function testing

\begin{tabular}{|c|c|c|c|c|c|c|c|}
\hline Patient No & Age (y) & Sex & Sputum & $\underset{(\%)}{F E V, / F V C}$ & $\begin{array}{l}\underset{(\%)}{R V / T L C} \\
(\%)\end{array}$ & $\begin{array}{l}\text { KCO } \\
(\mathrm{mmol} / \mathrm{min} / \mathrm{kPa} / \mathrm{l})\end{array}$ & Smoking status \\
\hline $\begin{array}{r}1 \\
2 \\
3 \\
4 \\
5 \\
6 \\
7 \\
8 \\
9 \\
10 \\
11 \\
12 \\
13 \\
14 \\
15\end{array}$ & $\begin{array}{l}63 \\
60 \\
35 \\
56 \\
70 \\
55 \\
62 \\
60 \\
66 \\
36 \\
47 \\
30 \\
53 \\
56 \\
43\end{array}$ & $\begin{array}{l}F \\
F \\
M \\
F \\
F \\
M \\
F \\
M \\
F \\
F \\
F \\
M \\
F \\
F \\
M\end{array}$ & $\begin{array}{l}\text { Purulent } \\
\text { Purulent } \\
\text { Purulent } \\
\text { Purulent } \\
\text { Purulent } \\
\text { Purulent } \\
\text { Purulent } \\
\text { Purulent } \\
\text { Purulent } \\
\text { Purulent } \\
\text { Purulent } \\
\text { Purulent } \\
\text { Purulent } \\
\text { Purulent } \\
\text { Purulent }\end{array}$ & $\begin{array}{l}28.9(72.7) \\
69 \cdot 8(72.5) \\
64.5(81.6) \\
34.3(73.5) \\
72.0(73.3) \\
32.0(76.2) \\
41.3(77.0) \\
53.3(74.4) \\
\\
65.7(80.4) \\
62.1(75.4) \\
57.3(82.9) \\
27.9(75.5) \\
61.2(75.0) \\
63.4(79.7)\end{array}$ & $\begin{array}{l}66 \cdot 3(38 \cdot 4) \\
50 \cdot 8(38 \cdot 4) \\
36 \cdot 0(28 \cdot 0) \\
52 \cdot 8(36 \cdot 8) \\
44 \cdot 8(41 \cdot 1) \\
44 \cdot 4(33 \cdot 7) \\
44 \cdot 7(38 \cdot 3) \\
38 \cdot 9(35 \cdot 3) \\
\\
34 \cdot 1(31 \cdot 9) \\
39 \cdot 3(35 \cdot 1) \\
32 \cdot 7(26 \cdot 6) \\
54 \cdot 4(35 \cdot 9) \\
47 \cdot 5(37 \cdot 1) \\
39 \cdot 2(30 \cdot 3)\end{array}$ & $\begin{array}{l}1.50(1.63) \\
2.21(1.63) \\
2.42(1.75) \\
2.19(1.67) \\
1.55(1.60) \\
1.35(1.48) \\
1.86(1.64) \\
1.92(1.41) \\
1.93(1.83) \\
1.76(1.74) \\
1.68(1.81) \\
1.01(1.70) \\
1.67(1.66) \\
1.83(1.63)\end{array}$ & $\begin{array}{l}\text { S } \\
\text { NS } \\
\text { NS } \\
\text { NS } \\
\text { NS } \\
\text { S } \\
\text { NS } \\
\text { S } \\
\text { NS } \\
\text { NS } \\
\text { NS } \\
\text { NS } \\
\text { NS } \\
\text { S } \\
\text { NS }\end{array}$ \\
\hline
\end{tabular}

FEV -forced expired volume in 1 second; FVC - forced vital capacity; TLC-total lung capacity (determined by helium dilution); RV-residual volume; KCO-transfer factor for carbon monoxide (single breath) corrected for lung volume; NS-non-smoker (for more than two years); S-current smoker. The values in parentheses are those predicted for the patients' age and height. ${ }^{8}$

outpatients with radiographically proved bronchiectasis. All regularly produced purulent secretions daily and were studied while in a clinical stable state at least six weeks after a recognised exacerbation. Details of the patients are given in table 1. All gave informed consent to participation in the study.

Sputum was collected at the start of the study on the first day of antibiotic treatment from waking until the administration of the first dose of antibiotic. Treatment was continued for 14 days and sputum again collected on days 7 and 14. A further sample was collected on day 21 , one week after stopping treatment. A portion of the sputum collected (over a four hour period) on days 0,14 , and 21 was sent for routine bacteriological culture. A note was made of the macroscopic appearance (clear or purulent) and the remainder was ultracentrifuged at $50000 \mathrm{~g}$ for $90 \mathrm{~min}$. The supernatant was removed and stored at $-70^{\circ} \mathrm{C}$; the pellet was discarded. On each occasion during the period of sputum collection $10 \mathrm{ml}$ of venous blood was taken and allowed to clot. The serum was removed after centrifugation and stored at $-70^{\circ} \mathrm{C}$ with subsequent analysis.

Amoxycillin $250 \mathrm{mg}$ three times daily was given initially on an empirical basis in all patients except those who were allergic to penicillin (these two patients were treated initially with co-trimoxazole, two tablets twice daily, or tetracycline, $500 \mathrm{mg}$ four times daily). In patients whose sputum failed to show any response to this treatment the results of the sputum culture were reviewed and a course of the antibiotic indicated or of co-trimoxazole was prescribed at least two weeks later for a further 14 days and the study was repeated.

All sputum samples were analysed for the presence of elastase activity, the elastin agarose diffusion plate being used, ${ }^{9}$ and the activity was compared with that of a single batch of porcine pancreatic elastase (PPE; British Drug Houses). The results were expressed in $\mu \mathrm{g}$ porcine pancreatic elastase $/ 100 \mu \mathrm{l}$ sample (lower limit of detection $0.8 \mu \mathrm{g} / 100 \mu \mathrm{l}$; between batch coefficient of variation $7 \cdot 5 \%$ ). The albumin concentration was measured in both the sputum and the corresponding serum sample by rocket immunoelectrophoresis with a monospecific antiserum (Seward Laboratories). The ratio of sputum to serum albumin was calculated and multiplied by 100 for convenience as described previously. ${ }^{10}$

The significance of differences between results for each day of the collection was determined by the Wilcoxon rank sum test for paired data. The values reported are means with standard deviations in parentheses.

\section{Results}

\section{ANTIBIOTIC RESPONSE}

The bacterial isolates from the initial study in all 15 patients are summarised in table 2 . The most prevalent organism isolated was Haemophilus infuenzae, which occurred alone in eight of the patients and with Klebsiella sp in a further patient.

During the initial treatment 10 of the patients showed macroscopic clearing of their sputum (change from purulent to clear). Clearing did not depend entirely on the results of the initial sputum culture (table 2). Four patients in whom $H$ infuen$z a e$ was isolated failed to respond macroscopically despite receiving a two week course of an appropriate antibiotic. In three of these patients sensitive $H$ infuenzae organisms were still isolated at the end of the treatment (table 2). Two patients (the sputum 
Table 2 Results of bacterial culture for the 15 patients

\begin{tabular}{|c|c|c|c|c|}
\hline \multirow{2}{*}{$\begin{array}{l}\text { Patient } \\
\text { No }\end{array}$} & \multicolumn{2}{|l|}{ Before treatment } & \multicolumn{2}{|c|}{ End of treatment period } \\
\hline & Organism & Sensitive to antibiotic used & Organism & Sensitive to antibiotic used \\
\hline $\begin{array}{r}1 \\
2 \\
3 \\
4 \\
5 \\
6 \\
7 \\
8 \\
9 \\
10 \\
11 \\
12 \\
13 \\
14 \\
15\end{array}$ & $\begin{array}{l}\text { Haemophilus infuenzae } \\
\text { H infuenzae } \\
\text { None } \\
\text { Pseudomonas aeruginosa } \\
\text { Staphylococcus aureus } \\
\text { H infuenzae } \\
\text { H infuenzae } \\
\text { H infuenzae } \\
\text { H infuenzae } \\
\text { Streptococcus pneumoniae } \\
\text { H infuenzae, Klebsiella sp } \\
\text { H infuenzae } \\
\text { None } \\
\text { H infuenzae } \\
\text { Streptococcus pneumoniae }\end{array}$ & $\begin{array}{l}\text { Yes } \\
\text { Yes } \\
\text { No } \\
\text { No } \\
\text { Yes } \\
\text { Yes } \\
\text { Yes } \\
\text { Yes } \\
\text { Yes } \\
\text { No } \\
\text { Yes } \\
\text { Yes } \\
\text { Yes }\end{array}$ & $\begin{array}{l}\text { None } \\
\text { None } \\
\text { None } \\
\text { None } \\
\text { None } \\
\text { H infuenzae } \\
\text { None } \\
\text { None } \\
\text { H infuenzae } \\
\text { None } \\
\text { H infuenzae } \\
\text { None } \\
\text { Ps aeruginosa } \\
\text { Hparainfuenzae } \\
\text { None }\end{array}$ & $\begin{array}{l}\text { Yes } \\
\text { Yes } \\
\text { Yes } \\
\text { No } \\
\text { Not tested }\end{array}$ \\
\hline
\end{tabular}

growing in one case resistant Pseudomonas aeruginosa and in the other no pathogenic organism) showed macroscopic clearing despite bacteriological evidence suggesting that this should not happen.

The remaining five patients (those whose sputum failed to clear) were then given a two week course either of an antibiotic selected on the basis of the original bacterial isolate and sensitivity tests (one patient cephalexin and one tetracycline) or of cotrimoxazole. With this second treatment a further two patients showed macroscopic clearing of their sputum but the remainder continued to produce purulent secretions.

One of the remaining patients still producing purulent sputum was restudied four weeks later because of the persistence of sensitive $H$ infuenzae but again failed to respond to a two week course of an appropriate antibiotic.

\section{BIOCHEMICAL ASSESSMENT}

Biochemical assessment was carried out on samples from all 21 antibiotic studies on the 15 patients. All the initial samples of sputum showed the presence of elastase activity. The average value before the start of treatment was $6.51(3.22) \mu \mathrm{g}$ PPE $/ 100 \mu \mathrm{l}$ and this fell within the first week of treatment to $3.33(4 \cdot 71)$ $\mu \mathrm{g}$ PPE $/ 100 \mu \mathrm{l}$. By day 14 four patients were no longer producing sputum and the average value for the remander was $3.01(3.60) \mu \mathrm{g}$ PPE/100 $\mu \mathrm{l}$. Within seven days of the end of treatment, however, the average value had risen again to $4.96(3.28) \mu \mathrm{g}$ $\mathrm{PPE} / 100 \mu \mathrm{l}$. The results are summarised in figure 1 .

This change was accompanied by a similar fall in the sputum:serum albumin ratio, from an average value of $2.37(1.52) \times 10^{-2}$ before treatment to 1.85 $(1.47) \times 10^{-2}$ and $1.94(1.72) \times 10^{-2}$ on days 7 and 14 of treatment $(n=21, p<0.01 ; n=17, p<$ 0.05 ). Within seven days of the end of treatment, however, the ratio had again risen to $2.13(1.28) \times$ $10^{-2}$
Closer analysis of individual data showed that it was possible to change the secretions from purulent to mucoid on at least one antibiotic regimen in 12 of the 15 patients. This was associated with a disappearance of elastase activity from the sputum. The individual data are shown in figure 2 with the results from the nine cases in which the sputum did not clear macroscopically and the elastase activity persisted. All except one of the patients whose sputum showed clearing of both purulence and elastase activity did so within the first week of treatment and the elastase activity and purulence returned in all but two within seven days of the end of treatment The effect on sputum:serum albumin ratios was

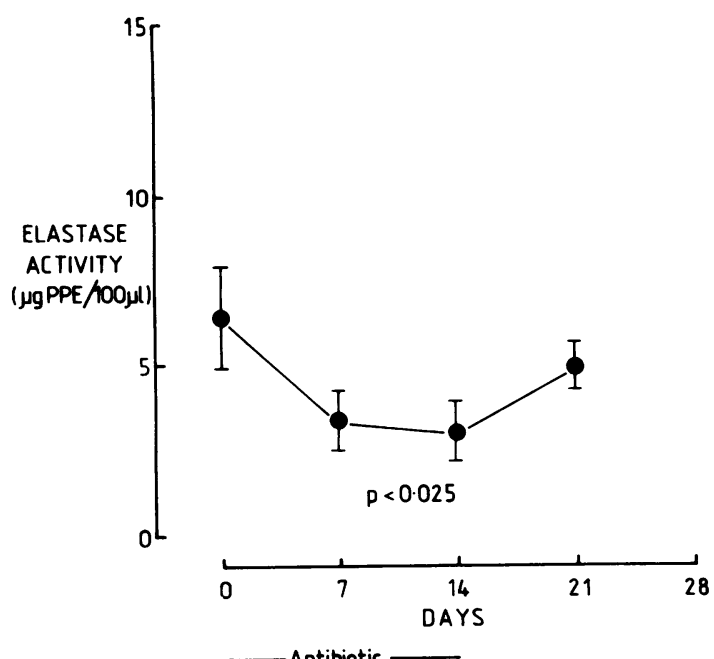

Fig 1 Mean content of elastase (expressed in terms of porcine pancreatic elastase (PPE) activity) in sputum from the 21 studies (15 patients) during and after treatment. The bars indicate one standard error. The significance of the change $(p)$ between day 0 and days 7 and 14 is shown. The results for day 14 are from 17 studies only. 


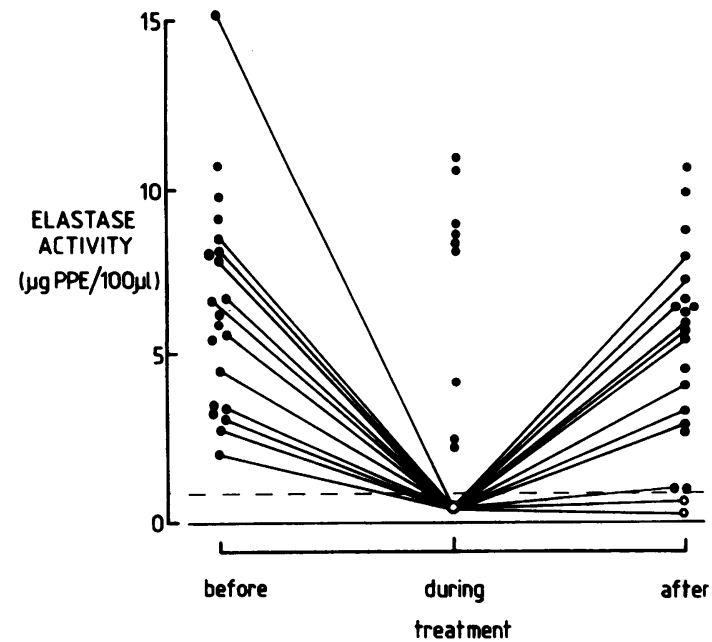

Fig 2 Individual elastase activities before, during (seven days after starting), and after (seven days after stopping) antibiotic treatment. The lines join results from the studies where elastase activity became absent. The horizontal dotted line indicates the lower limit of detection of elastase activity.

more dramatic in these 12 cases where the secretions cleared, falling from $2.32(1.56) \times 10^{-2}$ to $1.09(0.40) \times 10^{-2}$ within the first week $(\mathrm{p}<$ $0.005)$, but rising to $2.07(1.29) \times 10^{-2}$ within one week of the end of treatment. In contrast, the results

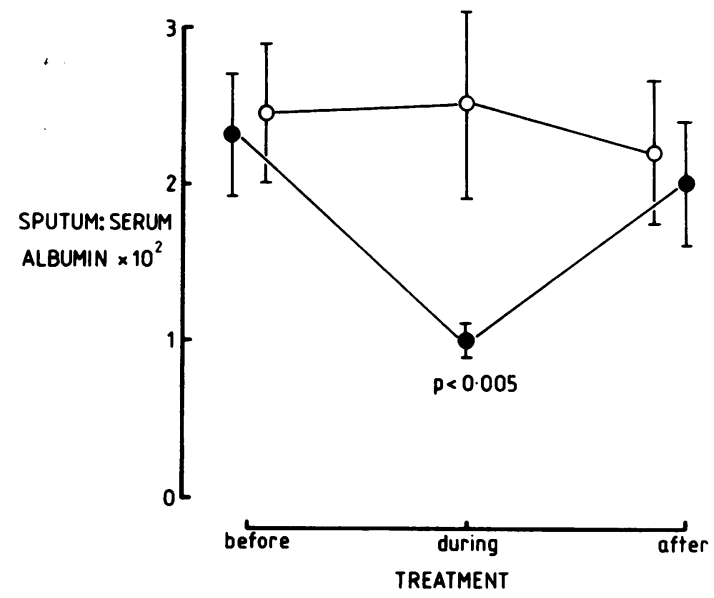

Fig 3 Mean sputum:serum albumin ratios before, during, and after antibiotic treatment for the 12 cases where elastase cleared (O) and the remaining nine where elastase persisted (O). The bars indicate 1 standard error. The results are given for the groups before antibiotic treatment, after seven days of treatment, and seven days after it had finished. There is a significant difference in sputum:serum albumin ratio during treatment between the group with clearing of elastase and the group in which elastase persisted. in the nine cases where the elastase activity failed to clear showed no change (day 0: $2.45(1.55) \times 10^{-2}$; day $7: 2.53(1.78) \times 10^{-2}$; day $21: 2.20(1.35) \times$ $\left.10^{-2}\right)$. These results are summarised in figure 3 .

\section{Discussion}

Previous studies ${ }^{1-3}$ have suggested that purulent secretions are a source of elastolytic enzymes that are potentially harmful to many of the tissues within the lung. " The present data confirm this finding, the initial samples from all our patients containing demonstrable elastase activity even while the patients were clinically stable.

The role of antibiotic treatment in such patients is uncertain. The usual clinical practice is to reserve antibiotic treatment for acute exacerbations of the disease characterised by clinical deterioration, pyrexia, or haemoptysis. Some patients, however, receive long term antibiotic treatment and it has been previously shown ${ }^{12}$ that continuous low dose treatment with tetracycline reduced symptoms and sputum volume and improved work record in patients with bronchiectasis. Despite this finding there is currently no evidence that continuous antibiotic treatment affects the long term prognosis of the disease.

The most common infecting organisms isolated from the secretions of bronchiectatic patients are $H$ infuenzae and Streptococcus pneumoniae. In the present study we isolated these organisms in 11 $(73 \%)$ of the patients, confirming the propensity of the organisms to colonise the secretions of clinically stable patients with bronchiectasis.

The sputum showed macroscopic clearing in $66.6 \%$ of patients treated with a broad spectrum antibiotic regimen known to be usually active in vitro against these organisms. Subsequent change to the antibiotics indicated by culture in the remaining patients led to macroscopic clearing in only two more $(13 \cdot 3 \%)$. Although clearing was generally predictable from the initial sputum culture (in eight of the 10 patients who showed clearing with the initial antibiotic regimen) there were exceptions and sputum containing organisms fully sensitive to amoxycillin often failed to show a response. Furthermore, clearing was achieved in samples where the initial culture had suggested no change should occur. In particular, four patients in whom $H$ infuenzae was cultured (in the absence of $\beta$ lactamase activity) failed to respond to conventional doses of antibiotics. This may be related to the fact that the minimum inhibitory concentration of antibiotic for $H$ infuenzae may not be adequately exceeded in all patients even in the case of amoxycillin, which has good penetration into secretions. ${ }^{13}$ The persis- 
tence of a sensitive organism in the secretions of these patients supports this hypothesis. In these cases there may be a better response to high doses of antibiotics ${ }^{14}$ and this possibility is being investigated. Interestingly, one patient showed clearing of the secretions even when no pathogenic organism was isolated (despite the use of a selective culture technique for $H$ infuenzae ${ }^{15}$ ) and two other patients showed clearing when the culture result suggested that the major pathogen was resistant to the treatment given ( $P$ s aeruginosa and Staphylococcus aureus). The results raise the possibility that the isolation of organisms in secretions from this group of patients is coincidental, with no cause and effect relationship.

The macroscopic clearing of the secretions was associated with distinct biochemical changes. When all 21 studies were considered together there was a significant fall in the sputum elastase concentration within one week of treatment. This was associated with a reduction in the sputum to serum albumin ratio, suggesting a fall in protein transudation and hence inflammation within the lung. ${ }^{16}$ The average results returned to the pretreatment level within one week of the end of treatment. This appears to be specifically related to the treatment, since patients producing elastase positive secretions usually continue to do so if no specific treatment is given ${ }^{3}$ and most patients studied here relapsed seven days after treatment had stopped.

The presence of elastase is a feature of purulent secretions, though not exclusively so. ${ }^{27}$ Although the neutrophil is known to release about $30 \%$ of its elastase content during phagocytosis ${ }^{17}$ and this seems the most likely explanation of the observed elastase concentrations, it is possible that ultracentrifugation itself resulted in the release of elastase activity into the sample. This possibility remains difficult to confirm or refute satisfactorily. We have, however, been unable to demonstrate elastase release from $13 \times 10^{6}$ neutrophils ultracentrifuged in $2 \mathrm{ml}$ of normal saline for 90 minutes (Stockley, unpublished observation). Furthermore, bronchoalveolar lavage fluid from patients with cystic fibrosis, which does not undergo prolonged ultracentrifugation, also shows the presence of free elastase activity. ${ }^{18}$ Hence the enzyme is likely to be largely extracellular in the secretions while still within the lung, thus having the potential for causing damage to the bronchial epithelium.

The sputum:serum albumin ratios were associated with the macroscopic nature and elastase content of the secretions. When the 12 cases where elastase activity cleared with antibiotic treatment were considered separately, an appreciable fall in the sputum:serum albumin ratio was seen. On the other hand, the results for the nine cases where the sputum failed to clear either macroscopically or in terms of elastase content showed no change in sputum:serum albumin ratio (fig 3 ). Within one week of the end of treatment the purulence and elastase activity returned in all but two of the cases and this was associated with an increase in the sputum:serum albumin ratio to the pretreatment level (fig 3). These results suggest a close association between purulence, elastase activity, and inflammation (as indicated by the sputum:serum albumin ratio). Antibiotic treatment given to these "clinically well" patients can reverse the purulent nature of the secretions, reduce the inflammatory response in the lung, and remove a potentially harmful enzyme. Indeed, recent studies have shown that these secretions have a detrimental effect on ciliary beat frequency in vitro and that this effect can be abolished by antibiotic treatment. ${ }^{19}$ Whether such treatment has a similarly beneficial effect in vivo and whether a maintained response can alter progression of the disease remains to be determined.

We thank Miss J Downs for typing the manuscript. Financial support was provided by Bencard and the General Hospital Bicentenary Appeal Fund; SLH was funded initially by the endowment fund.

\section{References}

' Lieberman J, Kaneshiro W. Inhibition of leucocyte elastase of purulent sputum by $\alpha_{1}$ antitrypsin. J Lab Clin Med 1972;80:88-101.

2 Stockley RA, Hill SL, Morrison HM, Starkie CM. The elastolytic activity of sputum and its relationship to purulence and lung function in bronchiectasis. Thorax 1984;39:408-13.

${ }^{3}$ Jackson AH, Hill SL, Afford SC, Stockley RA. Studies of sputum sol phase proteins and elastase activity in patients with cystic fibrosis. Eur J Respir Dis 1984; 65:114-24.

${ }^{4}$ Tegner H, Ohlsson K, Toremalm NG, Von Mecklenberg C. Effect of human leukocyte enzymes on tracheal mucosa and mucociliary activity. Rhinology 1979; 17: 199-206.

s Laurenço RV, Loddenkemper R, Carton RW. Patterns of distribution and clearance of aerosols in patients with bronchiectasis. Am Rev Respir Dis 1972; 106: $857-66$.

- Thurlbeck WM. In: Chronic airflow obstruction in lung disease. Philadelphia: WB Saunders, 1976:68-73.

7 Stockley RA, Burnett D. Alpha, antitrypsin and leukocyte elastase in infected and non infected sputum. $A m$ Rev Respir Dis 1979;120:1081-6.

* Cotes JE. Lung function: assessment and application in medicine. 4th ed. Oxford: Blackwell Scientific Publications, 1979.

' Ohlsson K, Tegner H. Granulocyte collagenase, elastase and plasma protease inhibitors in purulent sputum. Eur J Clin Invest 1975;5:221-7. 
${ }^{10}$ Stockley RA, Mistry M, Bradwell AR, Burnett D. A study of plasma proteins in the sol phase of sputum from patients with chronic bronchitis. Thorax 1979;34:777-82.

"Stockley RA. Proteolytic enzymes, their inhibitors and lung diseases. Clin Sci 1983;64:119-26.

12 Medical Research Council. Prolonged antibiotic treatment of severe bronchiectasis. $\mathrm{Br}$ Med J 1957; ii:255-9.

${ }^{13}$ May JR. The chemotherapy of chronic bronchitis and allied disorders. 2nd ed. London: English Universities Press, 1972:46-8.

${ }^{14}$ Cole PJ, Roberts DE, Davies SF, Knight RK. A simple oral antimicrobial regimen effective in severe chronic bronchial suppuration associated with culturable Haemophilus infuenzae. J Antimicrob Chemother 1983;11:109-13. is Roberts DE, Cole P. Use of selective media in bacteriological investigation of patients with chronic suppurative respiratory infection. Lancet 1980;i:796-7.

${ }^{16}$ Wiggins J, Elliott JA, Stevenson RD, Stockley RA. Effect of corticosteroids on sputum sol-phase protease inhibitors in chronic obstructive pulmonary disease. Thorax 1982;37:652-6.

${ }^{17}$ Ohlsson K. In: Reich E, Rifkin DB, Shaw E, eds. Proteases and biological control. New York: Cold Spring Harbor Laboratory, 1975:591-602.

1* Davis WB, Fells GA, Cherniak MS, DiSant Agnese P, Crystal RG. A role for neutrophils in the derangements of the bronchial wall characteristics of cystic fibrosis. Am Rev Respir Dis 1983;127, No 4 part 2:207.

${ }^{19}$ Smallman LA, Stockley RA. High dose amoxycillin. Lancet 1983;ii: 1258-9. 